
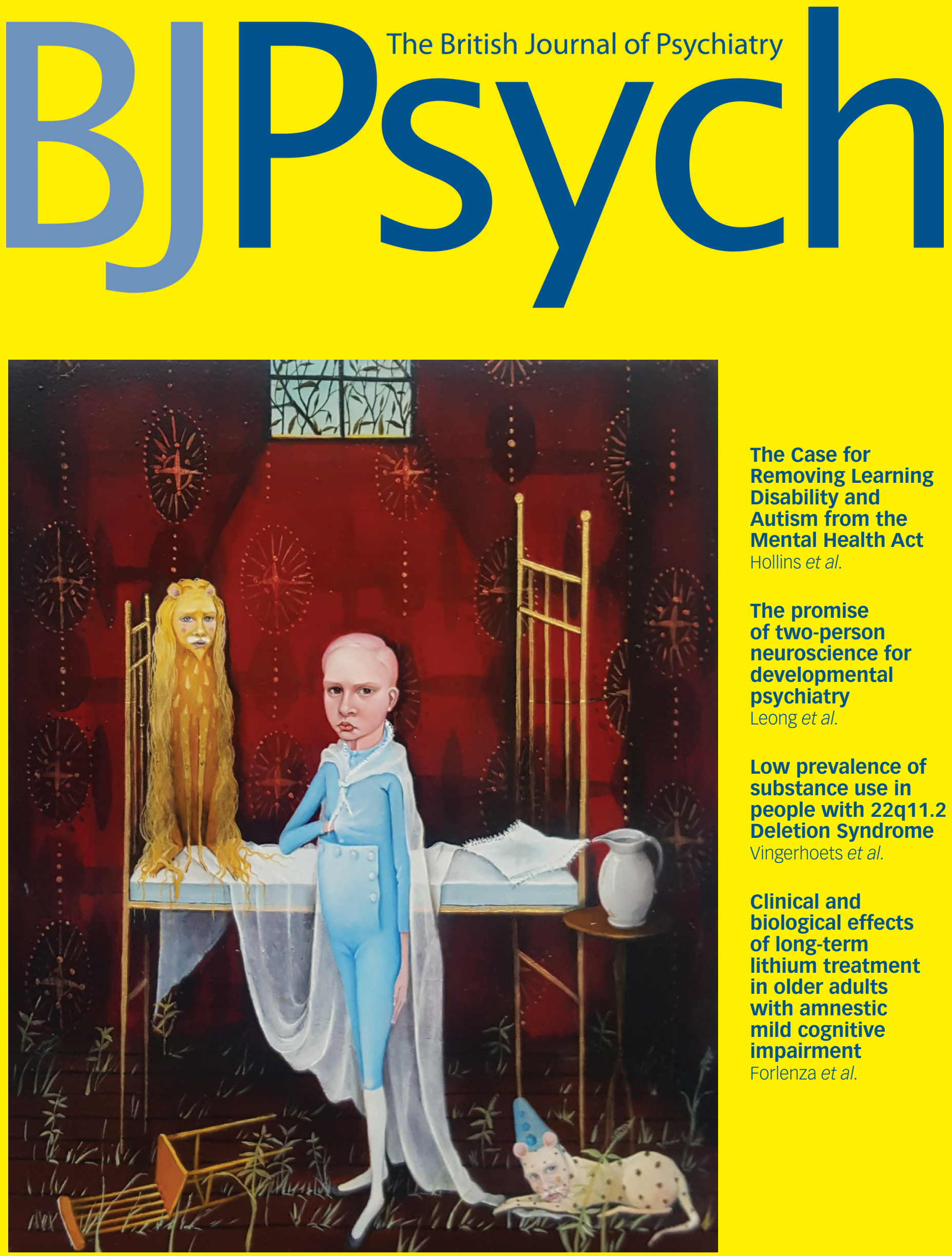

The Case for

Removing Learning Disability and

Autism from the Mental Health Act Hollins et al.

The promise of two-person neuroscience for developmental psychiatry

Leong et al.

Low prevalence of substance use in people with 22q11.2 Deletion Syndrome Vingerhoets et al.

\title{
Clinical and
} biological effects of long-term lithium treatment in older adults with amnestic mild cognitive impairment Forlenza et al. 


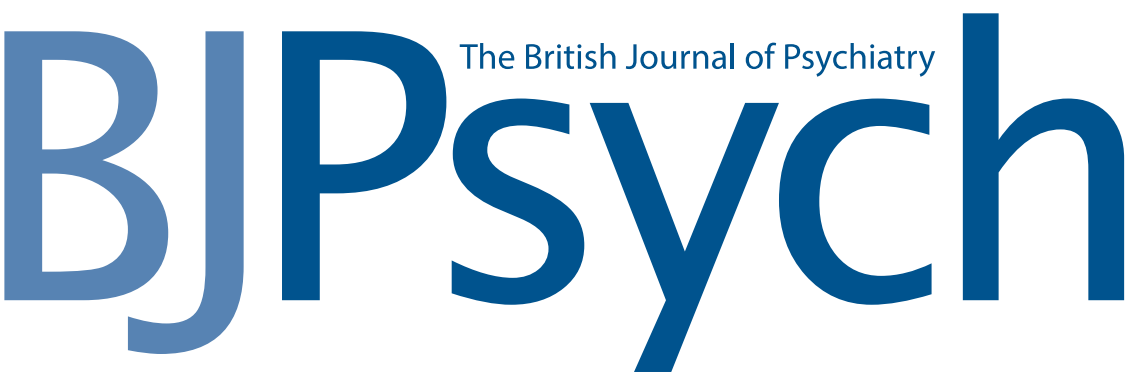

ISSN 0007 - 1250

Editor Kamaldeep Bhui CBE

\section{Deputy Editors}

Matthew Broome

William Lee

Gin Malhi

(Editorials Editor)

Giles Newton-Howes

(Reviews Editor)

Rachel Upthegrove

\section{Associate Editors}

Shehzad Ali

Mike Crawford

Elena Garralda

Joseph Hayes

Edgar Jones

Helen Killaspy

Anne Lingford-Hughes

Philip McGuire

Francis Anthony O'Neill

Jan Scott

James Shearer

Mustafa Soomro

\section{Editorial Advisors}

Sarah Byford

John Geddes

Martin Knapp

\section{International \\ Editorial Board}

Regi T. Alexander (UK)

Ricardo Araya (UK)

Allan Beveridge (UK)

(Book Reviews Editor)

Dinesh Bhugra (UK)

Jonathan Bisson (UK)

Alec Buchanan (USA)

Alistair Burns (UK)

Peter Byrne (UK)

(Executive Contents Editor)

Colin Campbell (UK)

(Correspondence Editor)

(Debate Editor)

Mary Cannon (Ireland)

Patricia Casey (Ireland)

Andrew Cheng (Taiwan)
Pamela Collins (USA)

John Cookson (UK)

Pim Cuijpers (The

Netherlands)

David Curtis (UK)

Michael Davidson (Israel)

Kimberlie Dean (Australia)

Colin Drummond (UK)

Sara Evans-Lacko (UK)

Joseph Firth (Australia)

Sophia Frangou (USA)

simon Gilbody (UK)

Peter Haddad (UK)

Madelyn Hicks (USA)

Matthew Hotopf (UK)

Louise Howard (UK)

Khalida Ismail (UK)

Assen Jablensky (Australia)

Navneet Kapur (UK)

Kenneth Kaufman (USA)

Steve Kisely (Australia)

Stephen Lawrie (UK)

Glyn Lewis (UK)

Shôn Lewis (UK)

Sean Lynch (UK)

Kwame McKenzie (Canada)

Nadia Micali (UK)

Marco Mula (UK)

Roger Mulder (New Zealand)

Frank Njenga (Kenya)

Aileen O'Brien (UK)

(Debate Editor)

Martin Orrell (UK)

Femi Oyebode (UK)

(Book Reviews Editor)

(Executive Contents Editor)

Michael Phillips (China)

Alexandra Pitman (UK)

Richard Porter

(New Zealand)

Thomas Schulze (Germany)

Sukhwinder Shergill (UK)

Najma Siddiqi (UK)

Cristiane Silvestre De Paula

(Brazil)

Emily Simonoff (UK)
Julia Sinclair (UK)

Swaran Singh (UK)

Dan Stein (South Africa)

Julia Stingl (Germany)

Athula Sumathipala (UK)

Nori Takei (Japan)

Graham Thornicroft (UK)

John Torous (USA)

Derek Tracy (UK)

J. L. Vazquez-Barquero

(Spain)

Simone Vigod (Canada)

Melanie Wall (UK)

Danuta Wasserman

(Sweden)

Simon Wessely (UK)

Richard Williams (UK)

Kiriakos Xenitidis (UK)

(Correspondence Editor)

Allan Young (UK)

\section{Trainee Editors}

Judith Harrison

\section{Statistical Advisors}

Eva Petkova

Pak Sham

Min Yang

\section{Staff}

Head of Publishing

Elizabeth Hay

Managing Editor

Alice Shuttleworth

Senior Publications

coordinator

Dianndra Roberts

\section{Past Editors}

Eliot Slater 1961-72

Edward H. Hare 1973-77

John L. Crammer 1978-83

Hugh L. Freeman 1984-93

Greg Wilkinson 1994-2003

Peter Tyrer 2003-13

The British Journal of Psychiatry is published monthly by the Royal college of Psychiatrists (a charity registered in England and Wales (228636) and in Scotland (SC038369)). The Journal publishes original work in all fields of psychiatry. Manuscripts for publication should be submitted online at https://mc.manuscriptcentral.com/bjpsych.

All papers in this journal are peer-reviewed. No person is permitted to take any role in the peer-review of a paper in which they have an interest, defined as follows: fees or grants from, employment by, consultancy for, shared ownership in, or any close relationship with, an organisation whose interests, financial or otherwise, may be affected by the publication of the paper.
British Journal of Psychiatry (ISSN 0007-1250) is published monthly. The six issues starting January 2019 comprise Volume 214, the six issues starting issues starting January 2019 comprise Volume 214 , the six issues starting
July 2019 comprise Volume 215 . Orders from non-members of the College, which must be accompanied by payment, may be sent to any bookseller or subscription agent or direct to the publishers: Cambridge University Press, Journals Fulfilment Department, UPH, Shaftesbury Road, Cambridge CB2 8BS, UK, email journals@cambridge.org; or in the USA, Canada and Mexico, to Cambridge University Press, Journals Fulfilment Department, 1 Liberty Plaza, Floor 20, New York, NY 10006, USA, email subscriptions_newyork@cambridge.org. Japanese prices for institutions are available from Kinokuniya Company Ltd, P.O. Box 55, Chitose, Tokyo 156, Japan.

The annual subscription prices (including delivery by air but excluding VAT) for Volumes 214/215 are as follows:

\begin{tabular}{|lcc|}
\hline & INSTITUTIONS & INDIVIDUALS \\
\hline Print and online & $£ 547 / \$ 976$ & $£ 441 / \$ 687$ \\
\hline Online only & $£ 449 / \$ 688$ & $£ 286 / \$ 447$ \\
\hline
\end{tabular}

Single issues are $\mathrm{f} 50$ (US\$89 in the USA, Canada and Mexico) plus postage. EU subscribers (outside the UK) who are not registered for VAT should add VAT at their country's rate. VAT registered subscribers should provide their VAT registration number. Claims for missing issues should be made immediately on receipt of the subsequent issue.

Queries from college members about missing or faulty copies should be sent to Customer Services, Cambridge University Press, email journals_societies@cambridge.org, tel. +44 (0)1223 326070.

\section{USPS ID Statement}

The British Journal of Psychiatry, ISSN 0007-1250, is published monthly by Cambridge University Press, UPH, Shaftesbury Road, Cambridge CB2 8BS, UK. The US annual subscription price is $\$ 976$ print and online/\$688 online only for institutions and \$687 print and online/\$447 online only for individuals. Airfreight and mailing in the USA by agent named WN Shipping USA, 156-15, 146th Avenue, 2nd Floor, Jamaica, NY 11434, USA. Periodicals postage paid at Jamaica NY 11431. US Postmaster: Send address changes to The British Journal of Psychiatry, WN Shipping USA, 156-15, 146th Avenue, 2nd Floor, Jamaica, NY 11434, USA. Subscription records are maintained at Cambridge University Press, UPH, Shaftesbury Road, Cambridge CB2 8BS, UK. Air Business Ltd is acting as our mailing agent.

\section{Online access}

British Journal of Psychiatry is hosted on the Cambridge Core service at https://www.cambridge.org/core/journals/the-british-journal-ofpsychiatry.

Information about the College's publications is available at https://mum. rcpsych.ac.uk.

Instructions to authors

Full instructions to authors are given at https://www.cambridge.org/core/ journals/the-british-journal-of-psychiatry/information/instructionscontributors.

\section{Advertising}

Correspondence and copy should be addressed to:

Stephen H. P. Mell, Advertising Manager, PTM Publishers Ltd, 41 Hart Close, Uckfield, East Sussex TN22 2DA, UK (email advertising@ptmpublishers. com; tel. 02086420162

Founded by J. C. Bucknill in 1853 as the Asylum Journal and known as the Journal of Mental Science from 1858 to 1963.

OThe Royal College of Psychiatrists 2019. Unless so stated, material in the British Journal of Psychiatry does not necessarily reflect the views of the Editor or the Royal College of Psychiatrists. The publishers are not responsible for any error of omission or fact.

Printed in Great Britain by Henry Ling Limited, The Dorset Press, 23 High East Street, Dorchester, Dorset DT1 1HD.

This journal issue has been printed on FSC TM-certified paper and cover board. FSC is an independent, non-governmental, not-for-profit organization established to promote the responsible management of the world's forests. Please see www.fsc.org for information. 


\section{BJPsych}

\section{Contents}

A43 Editorial Board

A45 Highlights of this issue

\section{Editorials}

633 The case for removing intellectual disability and autism from the Mental Health Act

Sheila Hollins, Keri-Michèle Lodge and Paul Lomax

635 Bartholomew the Englishman: On the Properties of Things Wikipedia of the Middle Ages - Psychiatry in literature Greg Wilkinson

636 The promise of two-person neuroscience for developmental psychiatry: using interaction-based sociometrics to identify disorders of social interaction

Victoria Leong and Leonhard Schilbach

\section{Review}

639 Cognitive deficits in problematic internet use: meta-analysis of $\mathbf{4 0}$ studies

Konstantinos Ioannidis, Roxanne Hook, Anna E. Goudriaan, Simon Vlies, Naomi A. Fineberg, Jon E. Grant and Samuel R. Chamberlain

\section{Papers}

647 Autism spectrum disorder diagnosis in adults: phenotype and genotype findings from a clinically derived cohort

Jack F. G. Underwood, Kimberley M. Kendall, Jennifer Berrett, Catrin Lewis, Richard Anney, Marianne B. M. van den Bree and Jeremy Hall

654 Intellectual disability and autism: socioeconomic impacts of informal caring, projected to 2030

Deborah Schofield, Melanie J. B. Zeppel, Robert Tanton, J. Lennert Veerman, Simon J. Kelly, Megan E. Passey and Rupendra N. Shrestha

661 Low prevalence of substance use in people with $22 q 11.2$ deletion syndrome

Claudia Vingerhoets, Mathilde J.F. van Oudenaren, Oswald J.N. Bloemen, Erik Boot, Esther D.A. van Duin, Laurens J.M. Evers, Ania M. Fiksinski, Elemi J. Breetvelt, Lisa D. Palmer, Elfi Vergaelen, Annick Vogels, Carin Meijer, Jan Booij, Genetic Risk and Outcome of Psychosis (GROUP) investigators, Liewe de Haan, Ann Swillen, Jacob A.S. Vorstman, Anne S. Bassett and Therese A.M.J. van Amelsvoort
668 Clinical and biological effects of long-term lithium treatment in older adults with amnestic mild cognitive impairment: randomised clinical trial

Orestes V. Forlenza, Márcia Radanovic, Leda L. Talib and Wagner F. Gattaz

675 Longitudinal associations of affective symptoms with mid-life cognitive function: evidence from a British birth cohort Amber John, Sarah-Naomi James, Urvisha Patel, Jennifer Rusted, Marcus Richards and Darya Gaysina

683 Understanding cognitive impairment in mood disorders: mediation analyses in the UK Biobank cohort Breda Cullen, Daniel J. Smith, Ian J. Deary, Jill P. Pell, Katherine M. Keyes and Jonathan J. Evans

\section{Columns}

691 Erratum

692 Book reviews

694 Contents of the American Journal of Psychiatry

694 Contents of BJPsych Advances

695 Kaleidoscope

\section{Cover picture}

Delusions of Grandeur by Heather Nevay.

I went to Glasgow School of Art, graduating in Printed Textiles. I have painted ever since, influenced by a long tradition of figurative art, and gradually finding my own style over the last 30 years or so.

This painting was inspired by a $\mathrm{BBC}$ radio programme ooking at various delusional states. I found it fascinating especially the episode on Delusions of Grandeur. It highlighted the spike in occurrence after the death of Napoleon. At one point there were 15 different people claiming to be him in a ward in a Paris hospital. It was a sensitive programme on a state of mind that I never realised could develop, so painting a version of it allowed me to explore the subject a little further. Using the imagery of children's play gave me a way to do this, whilst avoiding creating an overlysimplified narrative painting.

We are always looking for interesting and visually appealing images for the cover of the Journal and would welcome suggestions or pictures, which should be sent to Dr Allan Beveridge, British Journal of Psychiatry, 21 Prescot Street, London, E1 8BB, UK or bjp@rcpsych.ac.uk. 